\title{
Isolation of pathogenic yeasts in the air from hospital environments in the city of Fortaleza, northeast Brazil
}

\section{Authors}

Rossana A Cordeiro ${ }^{1,2,3}$

Raimunda SN

Brilhante $e^{1,2,3}$

Lydia DM Pantoja ${ }^{2}$

Renato E Moreira Filho ${ }^{1,2}$

Patrícia RN Vieira

Marcos FG Rocha ${ }^{1,2,4}$

André J Monteiro ${ }^{5}$

José JC Sidrim ${ }^{1,2,3}$

${ }^{1}$ Specialized Medical

Mycology Center

Universidade Federal do

Ceará, Fortaleza, Ceará,

Brazil.

${ }^{2}$ Postgraduate Program

in Medical Microbiology,

Universidade Federal do

Ceará, Fortaleza, Ceará,

Brazil.

${ }^{3}$ Postgraduate Program

in Medical Science,

Universidade Federal do

Ceará, Fortaleza, Ceará,

Brazil

${ }^{4}$ Postgraduate Program

in Veterinary Science,

Universidade Estadual do

Ceará, Fortaleza, Ceará,

Brazil.

${ }^{5}$ Department of Statistics and Applied Mathematics, Universidade Federal do Ceará, Fortaleza, Ceará, Brazil.
Submitted on: 05/03/2009 Approved on: 11/13/2009

\section{Correspondence to:}

Raimunda Sâmia N. Brilhante, Prof,

Rua Barão de Canindé, 210; Montese

CEP: 60.425-540

Fortaleza, CE,

E-mail: brilhante@ufc.br

We declare no conflict of interest.

\begin{abstract}
This paper reports the results of environmental surveillance of yeasts in specific areas of two tertiary local hospitals. From March 2007 to February 2008, samples from the air of two public hospitals were collected on a monthly basis. The samples were collected through passive sedimentation method (day and night exposure) of Petri dishes. A total of 240 air samples from 10 hospital environments were analyzed. These environments presented similar contamination levels, from which 80 fungi isolates were isolated: Candida parapsilosis $(\mathrm{n}=34)$, Rhodotorula spp. (19), Trichosporon asahii (11), C. tropicalis (8), C. albicans (4), C. glabrata (1), C. guilliermondii (1), C. krusei (1) and Saccharomyces spp. (1). Regarding the presence of yeasts and climatic conditions, there were 40 strains $(50 \%)$ in semi-critical areas (natural ventilation) and critical areas (air conditioned). Considering the presence of microorganisms with pathogenic potential, environmental monitoring is necessary to prevent possible hospital infections.
\end{abstract}

Keywords: environmental monitoring, air contamination, yeasts, hospitals.

[Braz J Infect Dis 2010;14(1):30-34] CElsevier Editora Ltda.

\section{INTRODUCTION}

The importance of bio-aerosols has been emphasized in recent decades due to their effect on human health. They have been implicated in conditions ranging from allergies to disseminated infections in susceptible patients. ${ }^{1}$ Different authors have reported the importance of these particles as transmitters of hospital infections, ${ }^{2,3}$ especially those caused by fungal isolates, as they act as epidemiologic markers of microbial contamination. ${ }^{4}$ Fungal infections of hospital origin have been gaining importance in recent years due to their progressive increase and their high rates of morbidity and mortality. ${ }^{5-7}$

In the hospital environment, the airborne microbiota is formed mainly by filamentous fungi, especially those belonging to the genera Aspergillus, Cladosporium, Paecilomyces, Penicillium, Scopulariopsis. ${ }^{8,9}$ Yeasts have also been found, of the genera Candida, Rhodotorula, Cryptococcus and Trichosporon,,$^{2,710,11,12}$ although there is less understanding about how they remain suspended in the air. All the mentioned genera have been described as potential human pathogens, ${ }^{8}$ especially the Candida genus, which is the main causative agent of hospital fungemia. ${ }^{13}$
Various studies suggest that the distribution of fungi in the air, in quantitative and qualitative terms, varies among geographic areas, and is also influenced by seasonal environmental and climatic factors, ${ }^{14,15}$ such as temperature, air humidity, time of day, wind speed and direction, presence of human activity, and type of ventilation in closed spaces. ${ }^{16}$ The difficulty of establishing a reliable method to measure the exposure to fungal particles in the air is one of the main impediments to clarifying the real impact of exposure on the development of fungal infections. ${ }^{17}$

Despite the need to monitor bio-aerosol levels in evaluating health risks, differences between automatic techniques and passive sedimentation techniques hamper results comparison. ${ }^{18}$ Automated techniques, although they are efficient in quantitative analysis, are of limited use because they require heavy and noisy equipment and need a constant power supply. ${ }^{17}$ The passive sedimentation technique is also limited because it does not permit an adequate quantitative analysis, but it is still widely recommended in the literature for use as a microbiological alert. ${ }^{7,9}$ 
Therefore, through the passive sedimentation method, bio-aerosol monitoring in hospitals can provide information for epidemiological investigation of nosocomial infectious diseases and research into airborne microorganism spread and control, as well as for quality control measures. ${ }^{19}$ This study involved the environmental monitoring of yeasts in specific areas of two tertiary local hospitals.

\section{MATERIAL AND METHODS}

\section{Ethical aspects}

This study was submitted to analysis of the research ethics committees of the two institutions and obtained approval in February 2007.

\section{Hospital environments}

The present study was conducted in two tertiary hospitals in the city of Fortaleza, Ceará, Northeast Brazil (Hospital A and Hospital B). The air sampling occurred during twelve months (March 2007 to February 2008), and 240 Petri dishes were analyzed both daytime and night time. In each hospital, five sectors were analyzed and grouped according to the risk of hospital infection ${ }^{20}$ into: critical areas (ICU and surgical ward), which were air conditioned, without negative pressure and without the use of HEPA filtering, and semi-critical areas (infirmaries), all with natural ventilation.

\section{Air sampling}

Air sampling from different areas was performed at two times, one during the morning, immediately after the cleaning and disinfecting service was carried out ( 8 to
10 a.m.), and another at night (8 to 10 p.m.), at the end of the regular shift, when there was no cleaning service. Sample collection was performed using the passive sedimentation method in $150 \mathrm{~mm}$ diameter Petri dishes containing Sabouraud dextrose agar medium (Sanofi ${ }^{\circledR}$, France), supplemented with vancomycin $(0.1 \mathrm{~g} / \mathrm{L})$ and polymyxin $\mathrm{B}(0.0075 \mathrm{~g} / \mathrm{L})$. The plates were exposed in each of the environments for two hours in each period, positioned $2 \mathrm{~m}$ high - roughly human respiration height. ${ }^{14}$ The Petri dishes were sealed and sent to the Specialized Medical Mycology Center (CEMM), Universidade Federal do Ceará.

\section{Fungal isolation and identification}

The samples were then incubated at $28^{\circ} \mathrm{C}$ for 10 days. A triage based on macroscopic characteristics was performed after growing the colonies on Petri dishes containing Sabouraud dextrose agar (Sanofi ${ }^{\circledR}$, France) to isolate all possible yeasts in each plate. All colonies with a glabrous aspect were cultured again in potato agar slants (Himedia ${ }^{\circledR}$, India). The yeast isolates were identified according to their morphological characteristics, biochemical profile, and growth in differential culture media. For identification of Candida species, the following tests were conducted: germinative tube, microculture in cornmeal agar with Tween 80 (Difco ${ }^{\circledR}$, USA), growth in CHROMagar $^{\circledR}$ (Candida, Paris, France), auxonogram, zimogram subcultures, and nitrogen assimilation. ${ }^{21}$ Identification of the Rhodotorula, Saccharomyces and Trichosporon species was based on morphological characteristics and biochemical profile. ${ }^{22}$

Table 1. Isolated yeasts in different areas of hospital A and hospital B from March/2007 to February/2008

\begin{tabular}{lcccc}
\hline \multirow{2}{*}{ Yeast } & \multicolumn{4}{c}{ Hospital environment } \\
& Hospital A & Hospital B & Hospital A & Hospital B \\
\hline C. albicans & 1 & - & 2 & 1 \\
\hline C. glabrata & - & - & - & 1 \\
\hline C. guilliermondii & - & - & 1 & - \\
\hline C. krusei & - & - & - & 1 \\
\hline C. tropicalis & 2 & 3 & 2 & 1 \\
\hline C. parapsilosis & 10 & 11 & 8 & 5 \\
\hline Rhodotorula spp. & 3 & 3 & - & 4 \\
\hline Saccharomyces spp. & - & 1 & 3 & - \\
\hline Trichosporon asahii & 2 & 4 & 25 & 15 \\
\hline Total isolates & 18 & 22 & & 2 \\
\hline
\end{tabular}


Table 2. Number of strains isolated from different areas of hospitals $A$ and $B$, regarding the type of ventilation and the period of sample collection

\begin{tabular}{|c|c|c|c|c|}
\hline \multirow[t]{2}{*}{ Area } & \multirow[t]{2}{*}{ Hospitals } & \multirow[t]{2}{*}{ Type of ventilation } & \multicolumn{2}{|c|}{$\begin{array}{l}\text { Period of the sample collection } \\
\text { (Number of Samples) }\end{array}$} \\
\hline & & & Diurnal (72) & Nocturnal (72) \\
\hline Critical Areas & A & & 13 & 5 \\
\hline \multicolumn{5}{|c|}{ Artificial } \\
\hline & B & & 12 & 0 \\
\hline Semi-critical Areas & A & & 8 & 17 \\
\hline \multicolumn{5}{|c|}{ Natural } \\
\hline & B & & 6 & 9 \\
\hline Total strains & - & - & 39 & 41 \\
\hline
\end{tabular}

\section{RESULTS}

The critical and semi-critical areas presented the same number of yeasts (40 strains per area). Four different yeast genera were isolated: Candida $(\mathrm{n}=49)$, Rhodotorula $(\mathrm{n}=19)$, Trichosporon $(\mathrm{n}=11)$ and Saccharomyces $(\mathrm{n}=1)$ (Table 1).

The semi-critical areas of Hospital A $(n=25)$ had a greater number of strains than the semi-critical areas of Hospital $B(n=15)$. All the genera were present in these areas, except Saccharomyces. There were also more yeasts present in these areas at night $(\mathrm{n}=26)$ than in daytime $(\mathrm{n}=14)$.

In critical areas, there were fewer yeasts isolated at Hospital A $(\mathrm{n}=18)$ than at Hospital B $(\mathrm{n}=22)$. All the species of yeasts were present, except for C. glabrata, C. guilliermondii, and C. krusei. Hospital B showed an even distribution in relation to the number or strains and collection period: 12 and 10 strains in daytime and at night, respectively. The distribution at Hospital A was skewed to daytime $(n=13)$ in relation to the night period $(\mathrm{n}=5)$.

Figure 1: Relationship between the number of yeast strains isolated by hospital area (critical and semi-critical) and according to rainfall level in Fortaleza, Ceará from March 2007.

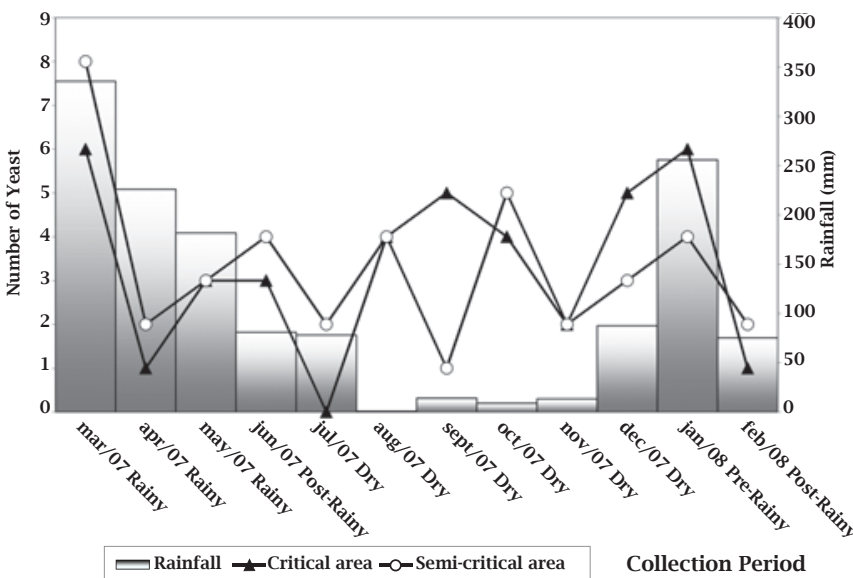

The number of yeasts was equally divided according to climate conditions, with 40 (50\%) found in areas with natural ventilation (semi-critical areas) and the same number in air conditioned areas (critical areas). In relation to the period of the day when the dishes were exposed, 39 (48.75\%) were observed in daytime samples and $41(51.25 \%)$ were found in night time samples (Table 2).

Finally, there was no correlation between fungal diversity in the air between the rainy and dry seasons (Figure 1).

\section{DISCUSSION}

In recent years, opportunistic fungal diseases have been characterized by their increased incidence, as well as the diversity of fungi isolated and infections greater severity. Yeasts of the Candida genus are outstanding among opportunistic fungi. ${ }^{13}$ In the present study, other genera besides Candida were isolated, such as Rhodotorula, Saccharomyces and Trichosporon. This is an important finding, since contact of these agents with patients can start the infectious process, depending on various factors, such as patient immunity. ${ }^{11,23}$

Candida is the most important genus of yeast implicated in human infections and is the major cause of fungemia. ${ }^{13}$ All the Candida species can cause a similar spectrum of diseases, ranging from thrush to invasive diseases such as arthritis, osteomyelitis, endocarditis, endophthalmitis and meningitis. However, there may be differences in severity and therapeutic options. ${ }^{24}$

Based on data descriptive statistical analysis, we observed that $C$. parapsilosis $(\mathrm{n}=34)$ was more frequently isolated than other Candida species. This species could be coming from human clinical material as well as from environmental samples. More recently, this species has emerged as an important nosocomial pathogen. ${ }^{25}$ Characteristics of C. parapsilosis that may relate to its increasing occurrence in nosocomial settings include skin frequent colonization and an ability to proliferate in glucose-containing 
solutions, with a resultant increase in adherence to synthetic materials. ${ }^{26} \mathrm{~A}$ study showed that $C$. parapsilosis was the main isolated agent, evidencing the importance of $C$. parapsilosis in candidemia episodes in a Brazilian tertiary care hospital in Northeast Brazil. ${ }^{25}$

C. tropicalis $(\mathrm{n}=8)$ was the second most isolated Candida species from the critical and semi-critical areas of Hospital A and B, followed by C. albicans $(\mathrm{n}=4)$, isolated from the semi-critical areas of Hospital A and B and critical areas of Hospital A. These species are considered the principal sources of candidiasis in humans. ${ }^{27}$ The others species of the Candida genus found (C. glabrata, C. guilliermondii and C. krusei) occurred only once $(\mathrm{n}=1)$. These three Candida species can also cause mucosal or systemic infections. ${ }^{24,28}$

The number of infections caused by non-Candida yeast species in immunosuppressed patients has increased in recent years, ${ }^{13}$ in both Brazilian and international health facilities. Their presence in the air deserves more attention because they have been emerging as pathogenic fungi, ${ }^{29}$ hence the presence of the genera Rhodotorula, Saccharomyces, and Trichosporon stands out.

In this context, regular environmental monitoring of hospital areas is important because the presence of bioaerosols can be rapidly transmitted by air, acting as a source of infectious agents. ${ }^{30}$ In particular, yeasts suspended in the air can settle directly on surgery wounds (direct contamination) or on the surface of the instruments used, as well as on the medical team's surgical gloves, and then be transmitted to the patient. ${ }^{31}$

According to the literature, airborne particles can have many origins. ${ }^{32}$ In environments with artificial ventilation, the air conditioning system, due to condensation trays, has been considered an important source of microorganism distribution. Thus, in environments with artificial ventilation, yeasts are probably transmitted by droplets produced by bio-aerosol equipment, as well as by coughing or sneezing, or even by routine procedures such as the withdrawal of vascular catheters. ${ }^{33}$ In this environment, due to control of temperature and humidity, we could not observe any significant differences between the day and night periods, except for the night-time period at Hospital A.

However, in environments with natural ventilation, the principal origins of air particles are believed to be ventilators, nebulizers, air humidifiers, plant vases, some foods, and people themselves. ${ }^{3}$ The presence of more sources of microorganisms in places with natural ventilation can explain the greater diversity of yeast species found in semicritical areas than in critical ones.

In relation to day time period, it was established that yeasts can be transmitted in both diurnal and nocturnal periods, a fact that can be explained by the small temperature variation between the day and night periods.
There was no significant relationship between the climatic data and air quality. This can be explained by the lack of well-defined seasons in northeast Brazil. Nevertheless, it disagrees with other studies, which show that fungal colonies in the region vary significantly with the season of the year. ${ }^{15}$

Finally, the hospital areas analyzed presented a similar contamination level, with the Candida genus being the most common, especially C. parapsilosis. Therefore, considering the presence of these microorganisms with pathogenic potential, air monitoring is essential to help prevent hospital infections. Among the preventive measures that should be considered are more frequent mechanical removal of dust, better cleaning and maintenance of air conditioners and other equipment that produce bio-aerosols, correction of room humidity, use of protective clothing by hospital personnel, and better staff training regarding the threats of infection by airborne microorganisms.

\section{ACKNOWLEDGEMENTS}

The authors thank CAPES (Coordination Office for University Improvement) for the research grant. This work was supported by the National Scientific and Technological Research Council (CNPq), Process 473881/2008-0.

\section{REFERENCES}

1. Gangneux JP, Bousseau A, Cornillet A, Kauffmann-Lacroix C. Control of fungal environmental risk in French hospitals. J Mycol Médicale 2006; 16:204-11.

2. Dacarro C, Picco AM, Grisoli P, Rodolfi M. Determination of aerial microbiological contamination in scholastic sports environments. J Appl Microbiol 2003; 95:904-12.

3. Afonso MSM, Souza ACS, Tipple AFV, Machado EA, Lucas EA. Condicionamento de ar em salas de operação e controle de infecção - uma revisão. Rev Eletr Enf 2006; 8:134-43.

4. Brasil, Ministério da Saúde Resolução. n.176, 24 out. 2000. Agência Nacional de Vigilância Sanitária. Orientação técnica sobre padrões referenciais de qualidade do ar interior em ambientes climatizados artificialmente de uso público e coletivo 2000. (Of. El. N.370/2000).

5. Pfaller MA. Nosocomial candidiasis: emerging species, reservoir, and modes of transmission. Clin Infect Dis 1996; 22:89-94.

6. Colombo AL. Epidemiology and treatment of hematogenous candidiasis: a Brazilian perspective. Braz J Infect Dis 2000; 4:113-8.

7. Centeno S, Machado S. Assessment of airbone mycoflora in critical areas of the principal hospital of Cumaná, state of Sucre, Venezuela Invest Clin 2004; 45:137-44.

8. Rainer J, Peintner U, Pöder R. Biodiversity and concentration of airbone fungi in a hospital environment. Mycopathologia 2001; 149:87-97.

9. Sanca S, Asan A, Otkun MT, Ture M. Monitoring Indoor Airborne Fungi and Bacteria in the Different Areas of Trakya University Hospital, Edirne, Turkey. Indoor Built Environ 2002; 11:285-92. 
10. Krajewska K, Krajewska-Kulak E, Lukaszuk C, Rolka H, Lach J, Karczewski J. Occurrence of fungal pathogens in the delivery rooms of a hospital obstetrics department. Ginekol Pol 2004; 75:451-6.

11. Pini G, Faggi E, Donato R, Fanci R. Isolation of Trichosporon in a hematology ward. Mycoses 2005; 48:45-9.

12. Wang CY, Wu HD, Hsueh PR. Nosocomial transmission of cryptococcosis. N Engl J Med 2005; 352:1271-2.

13. Moretti ML. A importância crescente das infecções fúngicas. Rev Panam Infectol 2007; 9:8-9.

14. Pei-Chih W, Huey-Jen S, Chia-Yin L. Characteristics of indoor and outdoor airbone fungi at suburban and urban homes in two seasons. The Sci of the Total Environ 2000; 253:111-8.

15. Huang CY, Lee CC, Li FC, Ma YP, Su HJJ. The seasonal distribution of bio-aerosols in municipal landfill sites: a 3-yr study. Atmosp Environm 2002; 36:4385-95.

16. Buttner MP, Stetzenbach LD. Monitoring airbone fungal spores in an experimental indoor environment to evaluate sampling methods and the effects of human activity on air sampling. Appl Environ Microb 1993; 59:219-26.

17. Tavora LGF, Gambale W, Heins-Vaccari EM, et al. Comparative performance of two air samplers for monitoring airborne fungal propagules. Braz J Med Biol Res 2003; 36:613-6.

18. Eduard W, Heederik D. Methods for quantitative assessment of airbone levels of noninfectious microorganims in highly contaminated work environments. Am Ind Hyg Assoc J 1998; 59:113-27.

19. Li C, Hou P. Bio-aerosol characteristics in hospital clean rooms. The Sci of the Total Environ 2003; 305:169-76.

20. Brasil, Ministério da Saúde. Coordenação de Controle de Infecção Hospitalar. Manual de Controle de Infecção Hospitalar. Brasília, Distrito Federal. 1985.

21. Gautret P, Rodier MH, Kauffmann-Lacroix C, Jacquemin JL. Case report and review. Onychomycosis due to Candida parapsilosis. Mycoses 2000; 43:433-5.
22. Hoog GS, Guarro J, Gene J, Figueiras MJ. Atlas of Clinical Fungi. Baarn/Delft: Centraalbureau voor Schinmelculture/Universitat Rovira i Virgilli, 2. ed. 1126 pp. 2000.

23. Pletinex M, Legein J, Vandenplas Y. Fungemia with Saccharomyces boulardii in a 1-year-old-girl with protacted diarrhea. J Pediatr Gastroenterol Nutr 1995; 21:113-5.

24. Pfaller MA, Yu WL. Antifungal susceptibility testing. New technology and clinical applications. Infect Dis Clin N Am 2001; 15:1227-61.

25. Medrano DJA, Brilhante RSN, Cordeiro RA, Rocha MFG, Rabenhorst SHB, Sidrim JJC. Candidemia in a brazilian hospital: the importance of Candida parapsilosis. Rev Inst Med Trop São Paulo 2006; 48:17-20.

26. Weems JJ. Candida parapsilosis: epidemiology, pathogenicity, clinical manifestations and antimicrobial susceptibility. Clin Infect Dis 1992; 14:756-66.

27. Calderone RA, Fonzi WA. Virulence factors of Candida albicans. Trends Microbiol 2001; 9:327-35.

28. Geiger AM, Foxman B, Sobel JD. Chronic vulvovaginal candidiasis: characteristics of women with Candida albicans, Candida glabrata, and no-Candida. Genitourin Med 1995; 71:304-7.

29. Nguyen $\mathrm{MH}$, Peacock JE, Morris AJ et al. The changing face of candidemia: emergence of non-Candida albicans species and antifungal resistance. Am J Med 1996; 100:617-23.

30. Alberti C, Bouakline A, Ribauad P et al. Relationship between environmental fungal contamination and the incidence of invasive aspergillosis in hematology patients. J Hosp Infect 2001; 48:198206.

31. Owers KL, James E, Bannister GC. Source of bacterial shedding in laminar flow theatres. J Hosp Infect 2004; 58:230-2.

32. Moscato U. Hygienic management of air conditioning systems. Ann Ig 2000; 12:155-74.

33. Siqueira LFG, Dantas E. Organização e método no processo de avaliação da qualidade do ar de interiores. Rev Brasindoor 1999; 3:19-26. 